\title{
LIGHTING: DESIGN AND CONSERVATION
}

History and Forecasts

Remarks by

JAMES EARL JEWETL, ATF, IESNA, CIES(HON)

Consultant in Lighting, San Francisco

on the occasion of the

75th Anniversary Conference of the ILLUMINATING ENGINEERING INSTITUTE OF JAPAN

ABSTRACT

It is fitting to celebrate this Diamond Jubilee at the start of the last decade of both a century and a millenium. For the Japanese millenia have come and gone but lighting has seen a revolution this century. Although the Institute appeared long after Sir Joseph Swan's invention of the electric lamp, the use of Kansai bamboo by Thomas Edison marked Japan's early contributions to lighting technology. From those beginnings we all moved steadily but placidly until the ten years of the first "energy crisis" produced more new light sources than had the hundred years since Edison's commercial product, the "wire in the bottle".

But technology alone, is not the answer in lighting. Light and vision are far too important in our lives to depend solely upon hardware. It is design (or the lack of it) which determines where light falls and how it affects our senses. The best possible design can make our lives better and safer, our. homes and work places more attractive, and provide the energy managenent and conservation which is required as we approach the end of the century.

However, energy bureaucrats must not be permitted to "turn out the lights"! Token gestures which suggest, but may not produce, lighting conservation must not interfere with modern industries which substitute the muscles of our eyes for the muscles of our backs. No amount of electrical energy saved is worth an increased expenditure of human visual energy. The nightscape must not be taken from us as we achieve the leisure to enjoy it.

The years through 2000 will see improvements in lamp technology and controls. Will they see equal research on light, vision, and colour and on user acceptance of the lighting changes which design, technology, and conservation must bring?

Research that keeps human needs in step with lighting technology can lead us all into a new century of lighting excellence which will match the achievements of the Japanese Institute's past seventy-five years. 